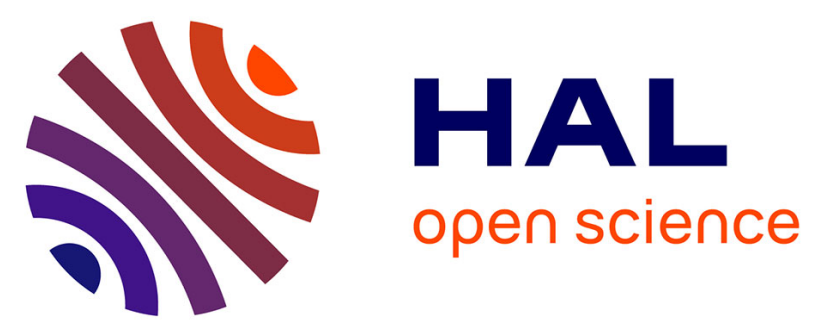

\title{
Fever in hospitalized HIV-infected patients in Western French Guiana: first think histoplasmosis
}

Vincent Vantilcke, Rachida Boukhari, Anne Jolivet, Cyrille Vautrin, Caroline Misslin, Antoine Adenis, Mathieu Nacher

\section{- To cite this version:}

Vincent Vantilcke, Rachida Boukhari, Anne Jolivet, Cyrille Vautrin, Caroline Misslin, et al.. Fever in hospitalized HIV-infected patients in Western French Guiana: first think histoplasmosis. International Journal of STD and AIDS, 2014, 25, pp.656 - 661. 10.1177/0956462413516299 . inserm-01082409

\section{HAL Id: inserm-01082409 https://www.hal.inserm.fr/inserm-01082409}

Submitted on 13 Nov 2014

HAL is a multi-disciplinary open access archive for the deposit and dissemination of scientific research documents, whether they are published or not. The documents may come from teaching and research institutions in France or abroad, or from public or private research centers.
L'archive ouverte pluridisciplinaire HAL, est destinée au dépôt et à la diffusion de documents scientifiques de niveau recherche, publiés ou non, émanant des établissements d'enseignement et de recherche français ou étrangers, des laboratoires publics ou privés. 


\title{
Fever in hospitalized HIV-infected patients in Western French Guiana: first think histoplasmosis
}

Vincent Vantilcke*, Rachida Boukhari ${ }^{\dagger}$, Anne Jolivet*, Cyrille Vautrin*, Caroline Misslin*, ,Antoine Adenis ${ }^{\# !}$, Mathieu Nacher ${ }^{\# \ddagger}$

*Centre hospitalier de l'ouest Guyanais, service de médecine, Saint Laurent du Maroni † Centre hospitalier de l'ouest Guyanais, Laboratoire Polyvalent, Saint Laurent du Maroni \#Centre d'investigation clinique épidémiologie clinique Antilles Guyane, CIE INSERM 802, Centre hospitalier de Cayenne.

$\mp$ Epidemiologie des parasitoses et mycoses tropicales, EA 3593, Université des Antilles et de la Guyane

\begin{abstract}
In Western French Guiana there was a dramatic increase in HIV-prevalence between 1990 and 2000. The present study describes the causes of fever among HIV patients hospitalized in the medical ward of the only hospital in the western part of French Guiana. A retrospective descriptive study was conducted between January $1^{\text {st }} 2008$ and June $30^{\text {th }} 2010$ in the department of medicine of Saint Laurent du Maroni Hospital. The main characteristics of 67 patients having presented with fever in the first 48 hours of hospitalization were described. Among patients with $\mathrm{CD} 4<200 / \mathrm{mm} 3$ the main febrile opportunistic infection was disseminated histoplasmosis (41.1\%). Among patients with CD4 counts $<50 / \mathrm{mm} 3$ and fever without focal points $85.7 \%$ had disseminated histoplasmosis. Three patients died and all had disseminated histoplasmosis. Disseminated histoplasmosis is the most common febrile
\end{abstract}


opportunistic infection in western French Guiana. Primary prophylaxis with itraconazole among immunocompromised patients seems warranted.

Key words : HIV, French Guiana, Fever, histoplasmosis, primary prophylaxis

\section{INTRODUCTION}

For the past twenty years, French Guiana has been the French territory with the highest HIV prevalence in mainland and overseas French territories. (1) The western part of French Guiana, which is separated from Suriname by the Maroni river, is very different from the rest of coastal French Guiana: The population consisting mostly of maroons (runaway slaves who formed independent settlements together) often lives in rural areas along the Maroni river, and is highly mobile between the French and Surinamese sides of the border. In the early 1990s there were no known HIV infections along the Maroni, but within a decade HIV prevalence exceeded $1 \%$ and has remained above $1 \%$ since. Boatmen transporting cargo along the river are thought to have been a bridging group between sex workers and the general maroon population, (2).

In the department of medicine of the Hospital of Saint Laurent du Maroni, the only hospital for western French Guiana, over 1 in 10 patients are admitted for an opportunistic infection linked to HIV. Outpatients receive free antiretrovirals and have access to the latest molecules, regular viral load monitoring, and viral genotyping. Clinicians and laboratories are very aware of histoplasmosis, therefore they have locally implemented standardized and proactive diagnostic and therapeutic procedures. If an immunocompromised patient comes with fever and no clear focal sign i.e. pyelonephritis, bacterial pneumonia, a bone marrow sample is rapidly taken, and direct examination followed by fungal culture are systematic. Physicians 
are prompt to initiate antifungal treatment when they suspect histoplasmosis may be causing fever (immunosuppression, fever and weight loss, liver enzyme abnormalities, cytopenia...). Presumptive treatment may consist of itraconazole in the absence of severity criteria, or liposomal amphotericin B in the presence of severity signs (3).

Given the general epidemiological and environmental particularities of French Guiana(4), and the specific conditions of western French Guiana (rural setting, populations living along the Maroni river, on the Surinamese border, a malaria endemic area, lower access to care), a retrospective study of medical records of HIV patients hospitalized for fever between January first 2008 and June 30th 2010 was conducted in this department.

The principal objective of the study was to identify the main febrile opportunistic infections associated with HIV in western French Guiana in order to refine diagnostic and therapeutic decisions in the light of the local epidemiology.

\section{Methods}

\section{Study design}

The study was retrospective and descriptive. It concerned patients admitted between January $1^{\text {st }} 2008$ and June $30^{\text {th }} 2010$. 
The 3 inclusions criteria were: HIV infection, age $>15$ years and hyperthermia $\left(>38^{\circ} \mathrm{C}\right)$. The HIV positive serostatus was either previously known or had been discovered at the time of admission.

Data was extracted from medical files identified by the hospital medical information system. The files of patients with HIV infection hospitalized in the department of medicine were then checked for the other 2 inclusion criteria. The analysis performed locally on anonymized data extracted from medical records from a single department in a single hospital, performed in order to improve patient care, falls within the authorization granted by the commission nationale informatique et libertés.

When the patients fulfilled the 3 inclusion criteria other variables were collected such as age, sex, nationality, date of HIV diagnosis, date of hospitalization, immunovirological data, treatment data, clinical and biological data, the final diagnoses, survival or death at the end of hospitalization. Mycologic diagnosis was performed in Saint Laurent du Maroni hospital either by direct examination of fluid or tissue samples, or culture, the gold standard of mycological examination. According to EORTC/MSG criteria for fungal diseases (5) proven histoplasmosis was considered when the fungus was recovered in culture from a specimen or when the microorganism was observed using histopathology or direct microscopy. Cases were considered probable on clinical arguments (hyperthermia, elevated ferritin, elevated LDH, elevated liver enzymes, pancytopenia) and evolution on presumptive antifungal treatment, and a positive H. capsulatum P.C.R(6). In French Guiana, to avoid deaths due to treatment delays, cases with a compatible clinical presentation (immunosuppression, hyperthermia, elevated ferritin, elevated LDH, elevated liver enzymes, pancytopenia) are treated. Here, we considered that patients with a favourable evolution on antifungals had histoplasmosis as reported in the conclusion of the hospitalisation in the patient records. 
The diagnosis of bacterial pneumonia relied on the clinical and radiological presentation, positive blood culture and/or pneumococcal antigen results and evolution after antibiotic treatment.

Patients upon admission get a standard biological screening, immunovirological screening, blood and urine cultures, chest $\mathrm{X}$ ray, serologies for toxoplasmosis, hepatitis, CMV, tuberculin test, gastric tubages, often they get PCR for CMV, they are screened for Cryptococcus (latex). If there are symptoms orienting towards specific diagnoses or organs ultrasounds, CT scanner, or MRI (in Cayenne) of the pertinent regions are available, endoscopy, bronchiolo-alveolar lavage, Cryptosporidium, Microsporidium, biopsies of liver or adenopathies are performed when indicated.

\section{Data analysis}

Data were entered in an excel file and then analyzed using STATA 8.2® (College Station, TX). The data analysis was descriptive. Univariate analysis was followed by bivariate analysis. Measures of association were obtained. Comparison of binary or qualitative variables was performed using the Chi2 test or Fischer's exact test when appropriate. Liver enzymes were considered to be elevated when they exceeded the laboratory threshold. Quantitative variables were compared using Mann Whitney's test or Student's test when appropriate. The sample size was insufficient to perform multivariate analysis.

\section{Results}

\section{Population characteristics}

There were 67 patients hospitalized during the study period for a total of 81 hospitalizations, hence 1.21 hospitalizations per patient. 
The sex-ratio was 1.48 males per female. The mean age was 40.6 years [range 27-59] in men and 38.97 years [range 16-74] in women without any significant difference between genders $(p=0.44) .61 \%$ of the patients were Surinamese, and $22 \%$ were French. $67.9 \%$ of hospitalizations concerned patients who already new their HIV status at the time of hospitalization (mean 3.8 years, SD 4.33 years).

\section{Diagnosis}

There were 24 diagnoses of histoplasmosis (14 certain, 4 probable, and 6 suspected) and 69 other diagnoses. Table 1 shows the Top 10 most common diagnoses. 52\% of patients with CD4 counts $>200$ had bacterial pneumonia.

Among patients with CD4<200/mm3, histoplasmosis was the main opportunistic infection. Among patients with CD4 $<100 / \mathrm{mm} 3$ and isolated fever, $68.4 \%$ had histoplasmosis. In those presenting a very profound immunosuppression $(\mathrm{CD} 4<50 / \mathrm{mm} 3)$ and fever without infectious focal signs, $85.7 \%$ had histoplasmosis.

In 33\% of cases, histoplasmosis was associated with another infection : Mycobacterium avium complex (2), cytomegalovirus(2) bacterial pneumonia, salmonellosis, shigellosis.

The diagnosis of histoplasmosis was mostly obtained by the culture of bone marrow aspirates (9/24) or colonic biopsy (4/24). The low sample size did not allow us to do statistics for other diagnoses.

Immune status at the time of hospitalization

Forty eight percent of hospitalized men vs $32 \%$ of women had less than 50 CD4 lymphocytes, and $73 \%$ of men vs $61 \%$ of women had less than $200 \mathrm{CD} 4 / \mathrm{mm} 3$ but again the difference failed to reach statistical significance ( $\mathrm{p}=0.2$ et 0.17 ).

\section{Clinical presentation of patients}

The mean duration of fever was 26.9 days [range 1-180]. 
The main clinical signs for severely immunocompromised patients $(C D 4<50 / \mathrm{mm} 3)$ relative to those with $\mathrm{CD} 4>=50 / \mathrm{mm} 3$ were weight loss $(89 \%)$ and diarrhoea $(58 \%) \quad(\mathrm{p}<0.001$ and $\mathrm{p}=0.004$, respectively).

Table 2 compares the demographics of patients with histoplasmosis and patients other diagnoses. Figure 1 shows the main clinical symptoms during histoplasmosis and other diagnoses. For histoplasmosis , $60 \%$ of patients were aware of their HIV status. Histoplasmosis was significantly associated with weight loss $(\mathrm{p}<0.001)$, diarrhoea $(\mathrm{p}=0.01)$ and isolated fever $(\mathrm{p}=0.02)$ (Figure 1). Patients with histoplasmosis had a longer median fever duration (30 days interquartile range (IQR) 53 days) than those without histoplasmosis (6 days $\mathrm{IQR}=12$ days), $P<0.001$.

\section{Biological presentation}

Severely immunocompromised patients had leukopenia and neutropenia, elevated ferritin, liver test abnormalities. CRP was significantly lower in immunocompromised patients (CD4 count<200) than patients with greater CD4 counts $(84,7 \mathrm{mg} / \mathrm{l}$ vs $195.4 \mathrm{mg} / \mathrm{l}$, respectively, $P<0.001)$.

Of the 24 histoplasmosis cases, 14 were confirmed by culture of peripheral blood, bone marrow, liver biopsy, intestinal biopsy, or lymph node biopsy. 4 were considered probable because of the presence of clinical arguments and a positive H. capsulatum P.C.R. Six patients with clinical arguments (hyperthermia, elevated ferritin, elevated LDH, elevated liver enzymes, pancytopenia) and a favourable evolution on presumptive treatment (favourable evolution on liposomal amphotericin B or itraconazole) were considered histoplasmoses. The biological signs associated with the diagnosis of histoplasmosis were pancytopenia $(\mathrm{p}<0.001)$, hyperferritinemia $(\mathrm{p}=0.001)$, and hepatic cytolysis $(\mathrm{p}<0.001)$ (Figure 2$)$. 


\section{Treatment and outcome}

Overall only one patient was still on antiretrovirals on admission. Treatment of histoplasmosis consisted of intraveinous liposomal amphotericin B $3 \mathrm{mg} / \mathrm{kg} /$ day for for severe patients until clinical improvement followed by itraconazole $400 \mathrm{mg} /$ day orally (with a $600 \mathrm{mg} /$ day loading dose for 3 days). For bacterial pneumonia, the treatment was amoxicillin + clavulanic acid $3 \mathrm{~g} /$ day or, in severe cases, ceftriaxone $2 \mathrm{~g} / 24 \mathrm{~h}$ combined with fluoroquinolones. Overall, there were 3 deaths out of 81 hospitalizations, thus a $3.7 \%$ mortality : all 3 deaths had disseminated histoplasmosis which amounts to a mortality of $12.5 \%$ for histoplasmosis.

\section{DISCUSSION}

This study emphasizes that histoplasmosis was, by far, the most frequent opportunistic infection on the border between French Guiana and Surinam, notably in the most profound cases of immunodepression $(\mathrm{CD} 4<50 / \mathrm{mm} 3)$. Indeed, a significant proportion of the hospitalized patients were severely immunocompromised. This particularly concerned older men, as observed elsewhere (7-9), a group that remains hard to reach for the HIV testing system.

The observed clinical and biological signs of histoplasmosis did not differ from the literature(10-12).

Throughout French Guiana, histoplasmosis fluctuates depending on the year between 20 to $30 \%$ of AIDS defining illnesses. In the present study, it concerned 23/56 (41.1\%) patients hospitalized for fever with less than $200 \mathrm{CD} 4 / \mathrm{mm} 3$ and up to $85.6 \%$ of patients hospitalized for isolated fever with less than $50 \mathrm{CD} 4 / \mathrm{mm} 3$. The mortality of histoplasmosis over the study 
period was $12.5 \%$ whereas historically it was around $40 \%$. The aggressive stance of local clinicians in investigating and treating suspected cases supported by a laboratory trained in fungal diagnosis probably explains this decrease in mortality. This emphasizes the crucial importance of awareness of this disease and prompt diagnosis, and when in doubt presumptive treatment.

Histoplasmosis was more frequent than pneumocystosis and toxoplasmosis which require primary prophylaxis as soon as CD4 counts drop below 200/mm3. This high incidence of histoplasmosis in western French Guiana suggests primary prophylaxis should be implemented in immunocompromised patients. The American society of infectious diseases recommends itraconazole prophylaxis as long as CD4 counts are $<150 / \mathrm{mm} 3$ in endemic areas where the incidence of histoplasmosis is greater than 10 cases for 100 person-years (13). In French Guiana the incidence of histoplasmosis is 15 cases per 100 person-years for patients with CD4 counts $<100 / \mathrm{mm} 3$. If this prophylaxis had been initiated in our patients, 15 histoplasmoses out of 24 could have been avoided since these patients knew their HIV status before being hospitalized.

Histoplasmosis has been documented in French Guiana and Brazil(14). There are fewer data in other countries of the Guiana shield, from which a significant number of patients are followed in Saint Laurent du Maroni. Given the fact that imported cases from Suriname have been reported in the netherlands (15-17) and that diagnosis is difficult, the most likely hypothesis is that it is underdiagnosed on the Guiana Shield, emphasizing the need for simple reliable diagnostic tools in resource limited countries.

In our study, tuberculosis was rather infrequent with only 2 documented cases. This is surprising because the incidence of tuberculosis is high representing the 4th opportunistic 
infection. The living conditions in Western French Guiana are more rural than in Cayenne, which may explain the lower incidence of tuberculosis.

The low frequency of cryptococcosis is somewhat surprising since in some brazilian series over $50 \%$ of systemic mycotic infections were cryptococcosis (18). Environmental and weather conditions could influence the incidence of histoplasmosis(4) which again suggests acute infections are significant and points towards prophylaxis..

Although the sample size was small, the present study gives a snapshot of the importance of histoplasmosis in this amazonian region. The risk of death should incite clinicians to suspect it first in front of isolated fever in an immunocompromised patient. Histoplasmosis is the most commonly found opportunistic infection associated with AIDS in this region and primary prophylaxis in patients with CD4 counts $<150 \mathrm{~mm} 3$ could be indicated(19). Although it has shown no significant impact on survival in the USA, it has shown significant incidence reduction(20). It could also be cost effective in limited resource contexts. Simple diagnostic tools are needed to facilitate diagnosis in resource-limited countries and increase awareness of this problem in South America.

Author contributions: Conceived the study: VV; designed the study: VV, RB, CV, CM, $\mathrm{MN}$; Analysed the data: VV, MN; interpreted the data: VV, RB, CV, AJ, CM, AA, MN; Drafted the manuscript: MN; Critically revised the manuscript for intellectual content: VV, RB, CV, AJ, CM, AA, MN; Read and approved the final version : VV, RB, CV, AJ, CM, AA, MN. Guarantor of the paper MN.

Funding: "This research received no specific grant from any funding agency in the public, commercial, or not-for-profit sectors." 
Competing interests: None declared.

Ethical approval: Not required.

\section{References}

1. Nacher M, Vantilcke V, Parriault MC, Van Melle A, Hanf M, Labadie G, et al. What is driving the HIV epidemic in French Guiana? Int J STD AIDS. May;21(5):359-61.

2. Gaubert Maréchal Emilie JA, Van melle Astrid, Parriault Marie Claire, Basurko Celia, Adenis Antoine, Hanf Matthieu, Vantilcke Vincent, Halfen Sandrine, Nacher Mathieu. Knowledge, attitudes, beliefs, practices on HIV/AIDS among boatmen on the Maroni river: a neglected bridging group? Journal of AIDS and clinical research. 2012.

3. Couppie P, Sobesky M, Aznar C, Bichat S, Clyti E, Bissuel F, et al. Histoplasmosis and acquired immunodeficiency syndrome: a study of prognostic factors. Clin Infect Dis. 2004 Jan 1;38(1):134-8.

4. Hanf M, Adenis A, Couppie P, Carme B, Nacher M. HIV-associated histoplasmosis in French Guiana: recent infection or reactivation? AIDS. Jul 17;24(11):1777-8.

5. De Pauw B, Walsh TJ, Donnelly JP, Stevens DA, Edwards JE, Calandra T, et al. Revised definitions of invasive fungal disease from the European Organization for Research and Treatment of Cancer/Invasive Fungal Infections Cooperative Group and the National Institute of Allergy and Infectious Diseases Mycoses Study Group (EORTC/MSG) Consensus Group. Clin Infect Dis. 2008 Jun 15;46(12):1813-21.

6. Simon S, Veron V, Boukhari R, Blanchet D, Aznar C. Detection of Histoplasma capsulatum DNA in human samples by real-time polymerase chain reaction. Diagn Microbiol Infect Dis. Mar;66(3):268-73.

7. Nacher M, El Guedj M, Vaz T, Nasser V, Randrianjohany A, Alvarez F, et al. Risk factors for late HIV diagnosis in French Guiana. AIDS. 2005 Apr 29;19(7):727-9.

8. Mugavero MJ, Castellano C, Edelman D, Hicks C. Late diagnosis of HIV infection: the role of age and sex. Am J Med. 2007 Apr;120(4):370-3.

9. Delpierre C, Cuzin L, Lauwers-Cances V, Marchou B, Lang T. High-Risk groups for late diagnosis of HIV infection: a need for rethinking testing policy in the general population. AIDS Patient Care STDS. 2006 Dec;20(12):838-47.

10. Pontes LB, Leitao Tdo M, Lima GG, Gerhard ES, Fernandes TA. [Clinical and evolutionary characteristics of 134 patients with disseminated histoplasmosis associated with AIDS in the State of Ceara]. Rev Soc Bras Med Trop. Jan-Feb;43(1):27-31.

11. Couppie P, Aznar C, Carme B, Nacher M. American histoplasmosis in developing countries with a special focus on patients with HIV: diagnosis, treatment, and prognosis. Curr Opin Infect Dis. 2006 Oct;19(5):443-9.

12. Huber F, Nacher M, Aznar C, Pierre-Demar M, El Guedj M, Vaz T, et al. AIDSrelated Histoplasma capsulatum var. capsulatum infection: 25 years experience of French Guiana. AIDS. 2008 May 31;22(9):1047-53.

13. Wheat LJ, Freifeld AG, Kleiman MB, Baddley JW, McKinsey DS, Loyd JE, et al. Clinical practice guidelines for the management of patients with histoplasmosis: 2007 update by the Infectious Diseases Society of America. Clin Infect Dis. 2007 Oct 1;45(7):807-25.

14. Nacher M, Aznar C, Blanchet D, Demar M, El Guedj M, Vaz T, et al. AIDS-related disseminated histoplasmosis in the greater Caribbean: how frequent is it? AIDS. 2006 Apr 4;20(6):951-2. 
15. Van der Schee AC, Dinkla BA, Festen JJ. Gonarthritis as only manifestation of chronic disseminated histoplasmosis. Clin Rheumatol. 1990 Mar;9(1):92-4.

16. Peters EJ, Kauffmann RH, Blok P. Fever and high lactate dehydrogenase in HIVpositive patients from the Antilles and Surinam: histoplasmosis? Neth J Med. 2006 Sep;64(8):302-6.

17. Joore JC, Marcelis JH, Sie-Go DM, Borleffs JC, Hoepelman IM. [Histoplasma capsulatum infection, a manifestation of AIDS unusual for The Netherlands]. Ned Tijdschr Geneeskd. 1990 Sep 29;134(39):1908-10.

18. Ribeiro LC, Hahn RC, Favalessa OC, Tadano T, Fontes CJ. [Systemic mycosis: factors associated with death among patients infected with the human immunodeficiency virus, Cuiaba, State of Mato Grosso, Brazil, 2005-2008]. Rev Soc Bras Med Trop. 2009 NovDec;42(6):698-705.

19. Nacher M. Adenis A. BC, Vantilcke V., Blanchet D. , Aznar C., Carme B., Couppié P. Primary prophylaxis of disseminated histoplasmosis in HIV patients in French Guiana: a cost effectiveness study. Am J Trop Med Hyg. 2013.

20. McKinsey DS. Histoplasmosis in AIDS: advances in management. AIDS Patient Care STDS. 1998 Oct;12(10):775-81. 